\title{
Preface to Second Edition
}

Although the body of theory reviewed in this Handbook has not changed dramatically since our first edition in 2016, the world around it has. These world-shaking changes are familiar to all of us. A surging authoritarian populism has challenged established norms and institutions of liberal democracy and of global order. Foreign tampering with democratic elections has become ever more brazen and the phenomenon of "fake news" has blindsided us. Progressive movements such as \#MeToo and Black Lives Matter have shaken our major institutions and challenged us to rethink our basic concepts of justice, while the rise of artificial intelligence and big data have presented new moral concerns about privacy and surveillance. And on top of all the momentous changes, the world has suffered through the COVID-19 pandemic, with its stunning implications for societal control and mobilization, and its lasting implications for how we work and live together.

Theories tend to develop on the scale of a decade or more, the result of the cumulative interaction between many smaller research agendas operating in parallel. They adapt over time to changing societal conditions and political events. In our opinion, they should avoid "faddishness" that jumps on the latest and most popular craze, lest they over-adapt to specific events or temporary conditions and hence miss the forest for the trees. Yet the events of the last five years are not really fads; they are fundamental in their implications and they require broad consideration.

What do the changes of the last five years tell us about theories of governance? This is a large and unruly question and we do not pretend to have a comprehensive answer. But we take it as opportunity to reflect on the theories presented in this book as a collection, and to ponder how the development of governance theories might respond in productive ways in the future.

The rise of authoritarian populism around the world has challenged many of the basic parameters of contemporary governance. In a very fundamental way, their economic nationalism challenges the globalization of the economy, which has had such a profound effect on the evolution of global governance. At least since the mid-1990s, the United States (US)-led multilateralism that characterized post-World War II international relations has partially disengaged from the task of international governance, while the rise of neoliberalism, the end of the Cold War, and the strengthening power of the Global South has significantly transformed the global landscape. International organizations - once the beacons of the multilateral order - have partially relinquished their centrality and transnational corporations and non-governmental organizations have to some degree stepped in to fill an emerging "governance gap" accentuated by economic globalization. Various strategies of "new governance"-such as corporate social responsibility and private regulation-were the products of this transformation (see Chapter 11 on "International relations theory," Chapter 44 on "Private governance," and Chapter 48 on "Transnational economic governance").

The Trump presidency exemplified the heightened tensions around global governance, expressing outright hostility to the tradition of US-led multilateralism, and denigrating traditional democratic allies and the United Nations. At the same time, it reintroduced a strong economic protectionism, raising questions about the free trade principles of the global economy. 
However, if anything, the result has been less of a thorough-going transformation of the international political economy and more of patchwork of inconsistent principles and increased tensions. The Biden administration has signaled a partial return to the status quo ante, but the governance gap deepened by the decline of US-led multilateralism is likely to continue, though probably with heightened turbulence, as the global response to COVID-19 suggests. If anything, the "regime complexity" observed by global governance scholars is likely to deepen. Walter Mattli and Jack Seddon's admonition to pay more attention to the distributional consequence of governance arrangements is likely to be even more relevant today (see Chapter 48).

Brexit has raised a related set of issues about global governance. In some respects, the European Union (EU) has carried on the tradition of multilateralism and fostered regional trade integration, and many perspectives on "new governance" have arisen from trying to make sense of its distinctive institutions and politics (see Chapter 27 on "Soft and hard governing tools," Chapter 46 on "Multi-level governance," and Chapter 47 on "EU and supranational governance"). The withdrawal of the United Kingdom from the EU represents an obvious nationalist challenge to multilateralism, though the future is difficult to discern. Although some scholars have argued that Brexit might actually strengthen the EU by opening a path toward deeper integration, others suggest that the populism represented by Brexit will embolden other EU member states to resist integration. However, many of the governance innovations in the European sphere reflect the limbo of whether the EU is a state or an international organization, and the current post-Brexit situation hardly settles that issue. Thus, we foresee more uncertainty about the types and strategies of governance in the EU, but do not currently envision a fundamental shift in the logic of governing as the attempts to involve relevant and affected actors to enhance both effectiveness and legitimacy are likely to continue.

While democratic forms of populism may serve as a corrective aligning disconnected elites with the people, the current forms of authoritarian populism have raised fundamental challenges to liberal democracy. Where populist parties have assumed power (Brazil, India, Hungary, Brazil and the US), the result has been "democratic backsliding" that has eroded the rule of law and bedrock principles of liberal politics. Populists have often adopted a more authoritarian stance toward the control and deployment of governing institutions, a disdain for minority rights, and a disregard for the public sphere. Perhaps most troubling, they have accentuated the divisive manipulation of political information. Is this development a fundamental challenge to governance, as described in many of theories outlined in this book? Yes, we would have to conclude that it is. In our view, much of the impetus for governance arises due to the increasing differentiation of society and politics. We see governance not so much as the retreat or erosion of the democratic state, but rather as the deepening pluralization of society and politics that aims to involve a plethora of public and private actors in governing society and the economy. However, this pluralization requires the state to invent new forms of engagement that share and organize political power in less hierarchical ways (see Chapter 7 on "State theory"). The authoritarian and anti-pluralist stance of many of the current populist movements represents a direct challenge to these pluralist modes of governance. Whereas recent populist movements thrive on division and contestation, and revert easily to authoritarian tactics, many governance strategies seek to promote cooperation and integration by devising modes of sharing power. The two approaches cannot easily coexist.

Yet here we are also in a world of limbo. Short of the triumph of populism, the forces that are pushing toward pluralism are equally strong. This situation suggests a fundamental point about governance theories. While there has been significant attention in the governance litera- 
ture to the concepts of representation (Chapter 15), deliberation (Chapter 16), power (Chapter 17), legitimacy (Chapter 18), accountability (Chapter 20) and transparency (Chapter 21) - and in this version of the Handbook we have also added an entry on trust by Bart Nooteboom (Chapter 19) - current events suggest to us that governance theories must engage more directly with the conditions that support or erode democracy. While governance theory has to some extent been attentive to conflict (work on collaborative governance-see Chapter 43-is in part an exploration of how to manage conflict), it has tended to focus more on cooperation and coordination as functional responses to complexity and interdependence.

The populist challenge to democracy also suggests the need to further deepen the engagement between governance theory and democratic theory (see Chapter 8 on "Democratic theory" and Chapter 40 on "Democratic network governance"). While governance theory has long been attentive to how governing arrangements incorporate the input of citizens (see Chapter 14 on "Public participation"), populism suggests the estrangement of citizens from the democratic state; and the need to channel citizen engagement in productive directions. Governance theories have important work to do in expanding our practical understanding of the range of ways that increasingly competent, critical and assertive citizens encounter and provide input into governing process.

While right-wing populists have challenged the basic precepts of liberal democracy, popular movements such as \#MeToo and Black Lives Matter have fundamentally challenged the status quo with respect to equity and inclusiveness. Equity has been one of the cornerstones of public administration theory, but it has been less visible in discussions of governance. The issue of inclusion, however, has been a prominent issue in the governance literature, both implicitly and explicitly (see Chapter 38 on "Normative considerations"). Inclusion often arises as an issue in the study of networks and collaboration, where there is often a tension about whom to include. While the governance literature is quite aware that different modes of governance shape whose voice gets expressed and heard, and that minority voices can easily be excluded, this is perhaps an area where governance theory could sharpen and deepen its analysis.

Populism and popular movements also raise another fundamental challenge for governance theories: how to incorporate social media into our theories. Social media raises challenges and opportunities for governing. First, by shaping new patterns and possibilities of communication, social media engenders new modes of coalition-building and interest expression, fundamentally reshaping the expression of politics. Second, it permits new voices to enter the public sphere and potentially shifts the balance of power between social groups and governing institutions. Third, social media changes the kind of information that has salience and influences how public debates unfold; with the exploitation of "fake news" representing the worst side of this changing info-scape. Fourth, social media fundamentally transforms the temporality of governance, speeding it up, and creating demands for rapid response.

Governance theories have mostly taken the changing character of digital technologies as a new and positive opportunity for improving governance, as captured by the term "e-governance." Digital technologies have provided the technological infrastructure for a range of emerging forms of governance (see Chapter 28 on "Information-based governance"). While this scholarship also discusses negative features of information technology, recent events suggest that governance theories need to do a more thorough job of incorporating the less savory aspects of social media and digital technology into our understanding of governance.

Concerns about the rise of artificial intelligence (AI) and big data have accentuated over the last five years. To some extent, AI and big data raise concerns that are already addressed by 
concepts in the governance theory toolkit, such as "transparency" (Chapter 21) and "governmentality" (Chapter 34). However, we suspect that concerns about privacy and surveillance are likely to become even more salient over the next decade. Moreover, AI and big data fundamentally change patterns of communication, interaction, customization and decision-making and it is likely that they will ultimately transform the tools and processes of governance. Governance theories will need to take these new modes of aggregating, distributing and valuing information into account as we try to understand emerging patterns of governance.

And finally, the big one: the COVID-19 pandemic. We will be digesting the lessons of this event for years. In many respects, however, it folds all the prior issues together. One of the noted lessons is that populist governments have performed poorly in responding to the emerging pandemic: denying its existence, rejecting multilateralism, advancing fake news and denigrating science. The pandemic has accentuated concern about the equitable provision of government and private sector resources, and elevated issues of legitimacy and trust. And it raises the practical and ethical salience of $\mathrm{AI}$ and big data.

Perhaps one of the major themes of the pandemic has been the relationship between knowledge and policy. This has been a central issue in governance theory for many years, particularly in research on risk governance (see Chapter 25 on "Risk"). In this version of the Handbook, we have added a new chapter by Paul Cairney on "Evidence" (Chapter 22). Having experienced the pandemic, every citizen will be impressed by the important - and somewhat tortured-relationship between evidence and policy. Are masks important? When and where should we wear them? Is the vaccine effective? Does it cause harmful side-effects? The relationship between science and policy is critical for governance, but rarely so straightforward as the phrase "evidence-based policy" makes it sound.

The COVID-19 pandemic called for rapid, complex and comprehensive policy responses by all levels of government, from local to international. The public policy literature has specialized in understanding the messy politics of policy-making punctuated by major "focusing events," though this body of work has tended to focus on understanding policy change over time frame of a decade or more. Still, policy process models offer a rich source of theory for understanding policy-making during the pandemic. In this edition of the Handbook, we include two new chapters relevant to this task: a chapter by Saba Sidikki on "Policy process frameworks" (Chapter 6) and a chapter by Jonathan Pierce and Alex Osei-Kojo on "The advocacy coalition framework" (Chapter 32).

As many have observed, the COVID-19 pandemic took on the quality of a "total mobilization," which typically occurs only in wars or major disasters. The role of the state in "steering" and "metagoverning" this total mobilization was at the heart of the pandemic response (see Chapters 26 and 49 on these concepts, respectively). Governments had to rapidly develop and implement regulatory strategies - hard and soft - to engage in broad-based societal controls that were scarcely imaginable outside of wartime situations (for relevant perspectives on regulation, see Chapter 9 on "Public law and regulatory theory" and Chapter 41 on "Regulatory governance").

The pandemic also raised many fundamental issues about modes of coordination and collaboration within and between governments and across the public-private divide; issues that have been foundational for governance theories. Although the pandemic response relied heavily on setting and enforcing rules for the conduct of public and private behavior, it also demanded elaborate forms of coordination and collaboration at all levels of government and society. Although the stresses and strains of coordination and collaborative were evident, there were 
bright notes as well, such as the successful public-private collaboration in the development of vaccines. Chapters on "Collective action theory" (Chapter 2), "Network" (Chapter 13), "Complexity theory and systems analysis" (Chapter 35), "Democratic network governance" (Chapter 40), and "Collaborative governance" (Chapter 43) contain relevant perspectives to help understand the successes and failures of collaboration and coordination.

An important feature of this total mobilization was that government and citizens had to co-produce the pandemic response. Mask use was a central feature of the pandemic response, and although it was in many cases authoritatively enforced, it also required a large degree of citizen cooperation (as evidenced in places where citizens refused to cooperate). Moreover, many countries saw a surge in volunteering and local collaboration involving citizens and civil society organizations helping those weak and elderly who were afraid to go out and in need of daily supplies and human contact. Co-production has been a theme of the public administration literature for many years, but it has rarely been envisioned on such a vast scale. In this version of the Handbook, we have included a new chapter on this topic by Tony Bovaird and Elke Loeffler (Chapter 39).

While science took on a central role in decision-making during the pandemic, uncertainty and the need to continually adapt and change were equally significant. All of us experienced the sense of constantly shifting rules, guidelines and strategies. While some of this might be attributed to muddled decision-making or political pressures, governance theories would also call attention to the inevitable need to flexibly adapt to changing circumstances and new information and exploit new opportunities to do things in new and better ways. Chapters in the Handbook on "Learning" (Chapter 23), "Innovation" (Chapter 24), "Complexity theory and systems analysis" (Chapter 35), and "Adaptive governance" (Chapter 50) speak directly to these issues. In addition, we have also added a chapter by Bernardo Rangoni on "Experimentalist governance," which envisions distributed actors engaging in "recursive learning" in response to uncertainty (Chapter 51).

In summary, this short reflection surfaces several themes for governance theories. The first and most important is that governance theories are essential for understanding the response to major societal events such as the COVID-19 pandemic. Indeed, the COVID pandemic makes it clear why we need a "tool kit" of different theories to address different aspects of the highly complex phenomena of "total mobilization." However, the second theme is that while governance theories have much to offer, they also need to be sensitive to fundamental political and economic challenges and shifts. Large-scale macro-changes in politics, economy and society are sometimes challenging to grasp or incorporate at the meso scale of most governance theories, but we need to be attentive to how these changes are transforming the basic parameters for governing. The intense populist and popular mobilization of the last few years suggests to us that governance theory needs to engage more fully with democratic theory, and to focus more on how modes of governance interact with societal conflict and equity. Changes in our communication and information environment have created new ways of engaging politics and they channel new ideas, perspectives and agendas, often at lightning speed. We need to find ways to account for these dynamics as we develop our next generation of theories of governance. 